\title{
Bedside Doppler ultrasound for the assessment of renal perfusion in the ICU: advantages and limitations of the available techniques
}

\author{
David Schnell ${ }^{1}$ and Michael Darmon $2,3^{*}$
}

\begin{abstract}
Three Doppler-derived techniques have been proposed to assess renal perfusion at bedside: Doppler-based renal resistive index (RI) which has been extensively but imperfectly studied in assessing renal allograft status and changes in renal perfusion in critically ill patients and for predicting the reversibility of an acute kidney injury (AKI), semi-quantitative evaluation of renal perfusion using colour-Doppler which may be easier to perform and may give similar information than $\mathrm{Rl}$ and contrast-enhanced sonography that may allow more precise renal and cortical perfusion assessment. These promising tools have several obvious advantages including their feasibility, non-invasiveness, repeatability and potential interest in assessing renal function or perfusion. However, several limits need to be taken into account with these techniques, and promising results remain associated with large areas of uncertainty. This editorial will describe more carefully advantages and limits of these techniques and will discuss their potential interest in assessing renal perfusion.
\end{abstract}

Keywords: Acute kidney injury; Resistive index; Doppler; Contrast-enhanced ultrasonography

Acute kidney injury remains associated with a high morbidity, a high short-term and long-term mortality and a tremendous economic impact [1]. Adequate preventive and curative strategies in this setting are still lacking. Indeed, specific strategies or medications tested over the last decades have been either inefficient or insufficiently validated to be recommended routinely [2]. The usual marker of acute kidney injury (AKI) is either poorly specific, poorly sensitive and/or delayed as regards the renal injury leading to an unavoidable late recognition of AKI and thus delayed interventions that may partly explain this situation [3]. Monitoring renal perfusion may theoretically allow individualized hemodynamic optimization that could ultimately limit renal dysfunction or AKI progression. This hypothesis is currently being investigated in an ongoing

\footnotetext{
* Correspondence: michael.darmon@chu-st-etienne.fr

${ }^{2}$ Medical-Surgical Intensive Care Unit, Saint-Etienne University Hospital, Avenue Albert Raimond, 42270 Saint-Priest-en-Jarez, Saint-Etienne, France ${ }^{3}$ Jacques Lisfranc Medical School, Jean Monnet University, Saint-Etienne, France

Full list of author information is available at the end of the article
}

study assessing mean arterial level optimization through Doppler-based resistive index (RI) in patients with septic shock (NCT01473498).

Ultrasonography (US) is performed routinely to assess renal and collecting system morphology [4]. B-mode US provides valuable information regarding anatomic features and pathological findings including search for signs suggestive of chronic renal disease, hydronephrosis, calcifications, cysts or solid masses. Renal Doppler US has been used to assess vasculature of either native or transplanted kidneys [5]. Although renal Doppler is valuable for assessing large arterial or venous abnormalities, this technique has been advocated in evaluating changes in intra-renal perfusion due to kidney diseases $[6,7]$. Three techniques have been evaluated with various results, interest and limitations in this field: Doppler-based renal RI which has been extensively but imperfectly studied in assessing renal allograft status $[8,9]$ and changes in renal perfusion in critically ill patients [10-12] and for predicting the reversibility of an AKI [13, 14], semi-quantitative evaluation of renal perfusion using colour-Doppler has been recently

\section{它}


suggested and may be easier to perform for similar information than RI $[4,15]$ and last contrast-enhanced sonography that may be more accurate in assessing renal perfusion [16].

All these techniques are rapid, non-invasive and repeatable, and they may help in assessing renal preclinical dysfunction or vascular damages, in evaluating risk of subsequent renal dysfunction and evaluating the severity of an acute kidney injury. Additionally, both RI and semiquantitative evaluation of renal perfusion can be performed in most patients by inexperienced operators following a half-day course [15]. On the other hand, reliability seems to be limited, clinical significance uncertain and diagnostic performance remains to be validated in adequately powered studies.

Doppler-based RI is an easy-to-perform evaluation usually obtained from a posterolateral approach [4, 7]. B mode allows location of the kidneys and detection of signs of chronic renal damage. Colour-Doppler or power-Doppler US allows then vessels' localization and a semi-quantitative evaluation of renal perfusion using colour-Doppler (Table 1 and Additional file 1: Figure S1a) [4]. Either the arcuate arteries or the interlobar arteries are then insonated with pulsed wave Doppler and RI (Pourcelot index) calculated according to the following formula: $R I=[[$ peak systolic shift - minimum diastolic shift]/peak systolic shift] (Additional file 1: Figure S1b) [4, 7]. If performed carefully, this measurement is reliable and the side-toside difference is usually less than $5 \%$ [17]. Renal RI may therefore appear as a simple and non-invasive tool easy to use at the patient bedside. Feasibility of the measure has been showed to be good, even in the settings of critically ill patients, and a recent study suggested a halfday training session might allow inexperienced operators to perform renal Doppler [15]. Interobserver reproducibility of RI measurement by senior radiologist or senior intensivist is considered excellent $[13,18]$. In critically ill patients, the interobserver reproducibility between a senior and inexperienced operator is good and measures seem accurate (absence of systematic bias) although associated with a lack of precision (interobserver $95 \%$ confidence interval of \pm 0.1 ) [15]. This lack of precision raises questions as regards the ability of RI to assess small

Table 1 Colour-Doppler for a semi-quantitative evaluation of intra-renal vascularization [4]

\begin{tabular}{ll}
\hline Stage & Quality of renal perfusion by colour-Doppler \\
\hline 0 & Unidentifiable vessels \\
1 & Few vessels in the vicinity of the hilum \\
2 & Hilar and interlobar vessels in most of the renal parenchyma \\
3 & Renal vessels identifiable until the arcuate arteries in the entire \\
& field of view
\end{tabular}

Bedside Doppler Ultrasound for the assessment of renal perfusion in the ICU: advantages and limitations of the available techniques. David SCHNELL et al. changes in renal perfusion or to be valuable in assessing sequential changes related to therapeutic interventions.

Doppler-based RI has been proposed to monitor renal perfusion in critically ill patients and to assess impact on renal perfusion of low-dose dopamine infusion and of gradual changes in mean arterial pressure in response to norepinephrine infusion or a fluid challenge $[10,12,19]$. The obtained results, although interesting, are difficult to interpret. First, as suggested by its name, the RI was initially considered an indicator of renal vascular resistance and blood flow. However, experimental and clinical studies have suggested correlation of RI with vascular resistance and blood flow to be weak [20,21]. The relationship between vascular resistance and RI is therefore limited even with large, non-physiological, pharmacologically induced changes in renal vascular resistances (RI changes of 0.047 IU $( \pm 0.008)$ per logarithmic increase in renal resistances) [22]. Moreover, these changes are to be considered in light of the limited precision of the technique (intra-observer $95 \%$ CI of \pm 0.05 ) $[13,14]$. In addition, this relationship seems to be linear only when vascular compliance is normal and progressively disappeared when vascular compliance decreases [2022]. Decreased vascular compliance may result not only from pre-existing subclinical vascular stiffness but also from acute change in renal or intra-abdominal pressure. Thus, the kidney being a capsulated organ, interstitial edema resulting from renal insult translates into increased subcapsular pressure ultimately decreasing renal perfusion [23] and being likely to decrease renal vascular compliance while increasing RI. Similarly, intraabdominal hypertension, or renal allograft compartment syndrome in renal transplant recipients, has been associated with increased RI [24, 25]. Several additional factors, including heart rate, mean arterial pressure, oxygen and carbon dioxide levels and age also influence RI value [7]. These experimental data, along with results of large studies in renal transplant recipients suggest therefore Doppler-based RI to be an integrative parameter rather than a substitute for renal biopsy or renal perfusion assessment [7, 9]. Despite its limitation, this integrative parameter may help in detecting early renal dysfunction or in predicting short-term reversibility of AKI $[6,13$, 14, 26]. Although preliminary results in this field are promising (Fig. 1), discrepant results have been published in this setting [27], and confirmatory studies are still needed.

Semi-quantitative renal perfusion assessment using colour-Doppler seems to be easier to perform than Doppler-based RI and may provide similar information regarding renal function $[4,15]$. Renal perfusion is semiquantitatively assessed using a four-stage scale (Table 1 and Additional file 1: Figure S1a). Results of both RI and semi-quantitative renal perfusion assessment are correlated 


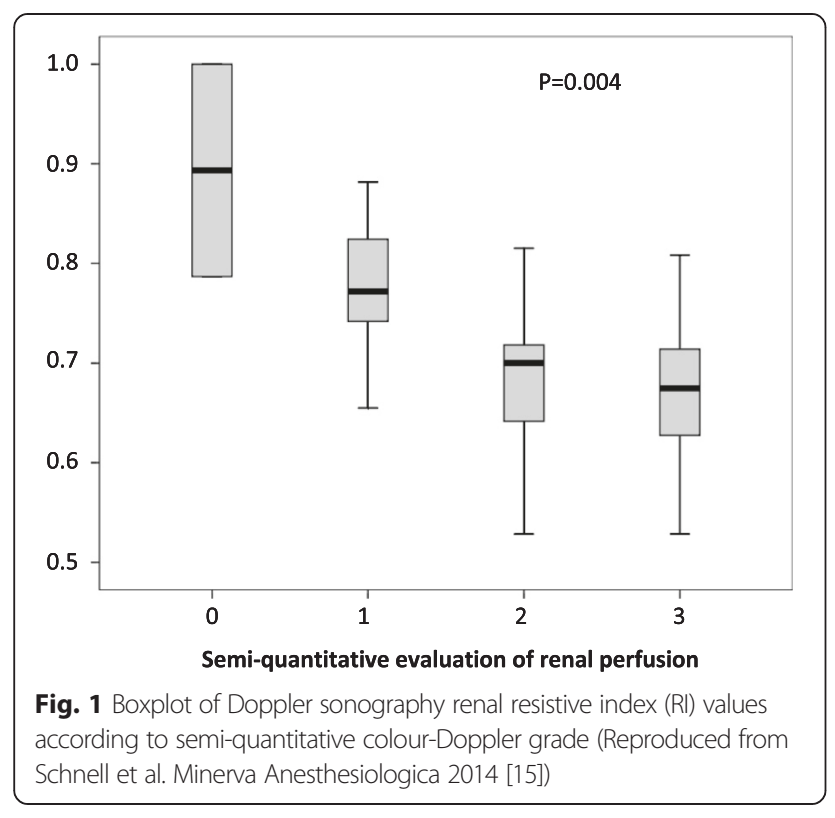

(Fig. 1), and reliability of the semi-quantitative renal perfusion seems to be similar to those of RI [15]. Similarly, semi-quantitative renal perfusion assessment seems to be associated with short-term reversibility of renal dysfunction which may theoretically help in predicting the need for renal replacement therapy and therefore optimal timing of this technique (Fig. 1) [15]. To the best of our knowledge, however, only a single preliminary report assessed the performance of this technique, and validation of these results are also needed.

Last, contrast-enhanced ultrasonography (CEUS) may be more accurate than the previously described techniques in assessing specifically renal perfusion. This technique associates low mechanical index (MI) ultrasonography and microbubble-based contrast agents and has been proposed to assess organ perfusion [16]. Hence, the intravascular distribution microbubbles along with their sensitivity to high-power acoustic pulses have been used to obtain destruction-refilling sequences, from which some parameters proportional to blood flow can be derived [16]. In a preliminary study performed in healthy volunteers, Schneider and colleagues demonstrated CEUS to detect renal cortical changes following angiotensine II or captopril administration [28]. Additionally, these changes were parallel to those of estimated renal plasma flow as estimated by paraaminohippurate clearance [28]. Two recent studies in critically ill patients assessed changes in CEUS-derived parameters in patients following either terlipressin [29] or norepinephrine administration [30]. Although CEUS was able to found significant changes in cortical perfusion, responses across patients were heterogeneous, unpredictable and of unclear relationship with patients' characteristics $[29,30]$. Last, interobserver variability was suggested to be high (up to $25 \%$ ) and discordant changes across perfusion parameters (suggesting in the same patients discordant changes in renal perfusion) found in up to $25 \%$ of the tested patients [30]. Hence, despite a promising initial report, CEUS has still to be demonstrated as both an accurate predictor of renal perfusion and a useful tool for clinical purpose.

These three techniques are promising. Renal Dopplerbased resistive index is easy to perform, rapid, noninvasive and repeatable. It is, however, doubtful as regards the numerous factors involved in RI, from the weak relationship between RI and renal vascular resistances to the large interobserver variation, that this tool could accurately assess renal perfusion changes. Nevertheless, renal Doppler has been found to be of potential interest in detecting subclinical renal vascular insults and in evaluating renal prognosis or short-term reversibility of an acute kidney injury and may therefore be clinically relevant at bedside in these indications. Preliminary data regarding semi-quantitative renal perfusion assessment suggest that this technique is easier to perform than RI and may provide similar information. Last, contrast-enhanced ultrasonography may theoretically be more accurate for bedside monitoring of renal perfusion than Doppler-based RI. However, despite promising results in healthy volunteers, this technique still has to be validated in this indication. More importantly, even though these techniques may prove to be useful in assessing renal function or renal perfusion, their clinical inputs at bedside for monitoring, preventive or therapeutic purposes remain theoretical and will have to be assessed.

\section{Additional file}

Additional file 1: Figure S1. Renal colour-Doppler ultrasonography showing renal vascularization and allowing semi-quantitative renal perfusion assessment (S1a). RI measurement using pulsed wave Doppler (S1b). Figures reproduced from Schnell et al. Intensive Care Medicine with authorization [7].

\section{Abbreviations}

AKI: Acute kidney injury; CEUS: Contrast-enhanced ultrasonography; MI: Mechanical index (PNP/ $/$ f, PNP being the peak negative pressure of the ultrasound wave derated by $0.3 \mathrm{~dB} \mathrm{~cm}^{-1} \mathrm{Mhz}^{-1}$ in megapascal and $f$ being the centre frequency of the ultrasound wave in $\mathrm{MHz}$ ); Rl: Doppler-based renal resistive index; US: Ultrasonography.

\section{Competing interests}

DS declares having no competing interest. MD declares having received research grant from MSD, research support from Astute Medical, financial support to organize educational sessions from MSD, Astellas and Jazz Pharma and speaker fees from Astellas, MSD, Bristol-Myers Squibb.

\section{Authors' contributions}

DS participated to systematic review of evidences, analysis of the available reports, drafting of the manuscript and review for important intellectual content. MD participated to systematic review of evidences, analysis of the available reports, drafting of the manuscript and review for important intellectual content. Both authors approved the final version. 


\section{Author details}

${ }^{1}$ Medical-Surgical Intensive Care Unit, Angoulême Hospital, Angoulême, France. ${ }^{2}$ Medical-Surgical Intensive Care Unit, Saint-Etienne University Hospital, Avenue Albert Raimond, 42270 Saint-Priest-en-Jarez, Saint-Etienne, France. ${ }^{3}$ Jacques Lisfranc Medical School, Jean Monnet University, Saint-Etienne, France.

\section{Received: 20 February 2015 Accepted: 5 May 2015} Published online: 28 May 2015

\section{References}

1. Nisula S, Kaukonen KM, Vaara ST, Korhonen AM, Poukkanen M, Karlsson S, Haapio M, Inkinen O, Parviainen I, Suojaranta-Ylinen R, Laurila JJ, Tenhunen J, Reinikainen M, Ala-Kokko T, Ruokonen E, Kuitunen A, Pettilä V, FINNAKI Study Group (2013) Incidence, risk factors and 90-day mortality of patients with acute kidney injury in Finnish intensive care units: the FINNAKI study. Intensive Care Med 39:420-428, doi:10.1007/s00134-012-2796-5

2. Kellum JA, Lameire N, for the KDIGO AKI Guideline Work Group (2013) Diagnosis, evaluation, and management of acute kidney injury: a KDIGO summary (part 1). Crit Care Lond Engl 17:204, doi:10.1186/cc11454

3. Legrand M, Darmon M (2014) Biomarkers for AKI improve clinical practice: yes. Intensive Care Med. doi:10.1007/s00134-014-3530-2

4. Barozzi L, Valentino M, Santoro A, Mancini E, Pavlica P (2007) Renal ultrasonography in critically ill patients. Crit Care Med 35:S198-205, doi:10.1097/01.CCM.0000260631.62219.B9

5. Platt JF (1997) Doppler ultrasound of the kidney. Semin Ultrasound CT MR 18:22-32

6. Platt JF, Rubin JM, Ellis JH (1991) Acute renal failure: possible role of duplex Doppler US in distinction between acute prerenal failure and acute tubular necrosis. Radiology 179:419-423

7. Schnell D, Darmon M (2012) Renal Doppler to assess renal perfusion in the critically ill: a reappraisal. Intensive Care Med 38:1751-1760, doi:10.1007/ s00134-012-2692-z

8. Radermacher J, Mengel M, Ellis S, Stuht S, Hiss M, Schwarz A, Eisenberger U, Burg M, Luft FC, Gwinner W, Haller H (2003) The renal arterial resistance index and renal allograft survival. N Engl J Med 349:115-124, doi:10.1056/ NEJMoa022602

9. Naesens M, Heylen L, Lerut E, Claes K, De Wever L, Claus F, Oyen R, Kuypers D, Evenepoel P, Bammens B, Sprangers B, Meijers B, Pirenne J, Monbaliu D, de Jonge H, Metalidis C, De Vusser K, Vanrenterghem Y (2013) Intrarenal resistive index after renal transplantation. N Engl J Med 369:1797-1806, doi:10.1056/NEJMoa1301064

10. Deruddre S, Cheisson G, Mazoit JX, Vicaut E, Benhamou D, Duranteau J (2007) Renal arterial resistance in septic shock: effects of increasing mean arterial pressure with norepinephrine on the renal resistive index assessed with Doppler ultrasonography. Intensive Care Med 33:1557-1562, doi:10.1007/s00134-007-0665-4

11. Duranteau J, Deruddre S, Vigue B, Chemla D (2008) Doppler monitoring of renal hemodynamics: why the best is yet to come. Intensive Care Med 34:1360-1361, doi:10.1007/s00134-008-1107-7

12. Lauschke A, Teichgräber UKM, Frei U, Eckardt K-U (2006) "Low-dose" dopamine worsens renal perfusion in patients with acute renal failure. Kidney Int 69:1669-1674, doi:10.1038/sj.ki.5000310

13. Lerolle N, Guérot E, Faisy C, Bornstain C, Diehl JL, Fagon JY (2006) Renal failure in septic shock: predictive value of Doppler-based renal arterial resistive index. Intensive Care Med 32:1553-1559, doi:10.1007/s00134-006-0360-x

14. Darmon M, Schortgen F, Vargas F, Liazydi A, Schlemmer B, Brun-Buisson C, Brochard L (2011) Diagnostic accuracy of Doppler renal resistive index for reversibility of acute kidney injury in critically ill patients. Intensive Care Med 37:68-76, doi:10.1007/s00134-010-2050-y

15. Schnell D, Reynaud M, Venot M, Le Maho AL, Dinic M, Baulieu M, Ducos G, Terreaux J, Zeni F, Azoulay E, Meziani F, Duranteau J, Darmon M (2014) Resistive index or color-doppler semi-quantitative evaluation of renal perfusion by inexperienced physicians: results of a pilot study. Anestesiol, Minerva

16. Schneider A, Johnson L, Goodwin M, Schelleman A, Bellomo R (2011) Bench-to-bedside review: contrast enhanced ultrasonography-a promising technique to assess renal perfusion in the ICU. Crit Care Lond Engl 15:157, doi:10.1186/cc10058
17. El Helou N, Hélénon O, Augusti M, Correas JM, el Rody F, Souissi M, Moreau JF (1993) Renal Doppler ultrasonography in the diagnosis of acute obstructions of the upper urinary tract. J Radiol 74:499-507

18. London NJ, Aldoori MI, Lodge VG, Bates JA, Irving HC, Giles GR (1993) Reproducibility of doppler ultrasound measurement of resistance index in renal allografts. Br J Radiol 66:510-513

19. Schnell D, Camous L, Guyomarc'h S, Duranteau J, Canet E, Gery P, Dumeni AS, Zeni F, Azoulay E, Darmon M (2013) Renal perfusion assessment by renal Doppler during fluid challenge in sepsis. Crit Care Med 41:1214-1220, doi:10.1097/CCM.0b013e31827c0a36

20. Bude RO, Rubin JM (1999) Relationship between the resistive index and vascular compliance and resistance. Radiology 211:411-417

21. Murphy ME, Tublin ME (2000) Understanding the Doppler Rl: impact of renal arterial distensibility on the $\mathrm{RI}$ in a hydronephrotic ex vivo rabbit kidney model. J Ultrasound Med Off J Am Inst Ultrasound Med 19:303-314

22. Tublin ME, Tessler FN, Murphy ME (1999) Correlation between renal vascular resistance, pulse pressure, and the resistive index in isolated perfused rabbit kidneys. Radiology 213:258-264

23. Herrler T, Tischer A, Meyer A, Feiler S, Guba M, Nowak S, Rentsch M, Bartenstein P, Hacker M, Jauch KW (2010) The intrinsic renal compartment syndrome: new perspectives in kidney transplantation. Transplantation 89:40-46, doi:10.1097/TP.0b013e3181c40aba

24. Kirkpatrick AW, Colistro R, Laupland KB, Fox DL, Konkin DE, Kock V, Mayo JR, Nicolaou S (2007) Renal arterial resistive index response to intraabdominal hypertension in a porcine model. Crit Care Med 35:207-213, doi:10.1097/ 01.CCM.0000249824.48222.B7

25. Ball CG, Kirkpatrick AW, Yilmaz S, Monroy M, Nicolaou S, Salazar A (2006) Renal allograft compartment syndrome: an underappreciated postoperative complication. Am J Surg 191:619-624, doi:10.1016/j.amjsurg.2006.02.013

26. Schnell D, Deruddre S, Harrois A, Pottecher J, Cosson C, Adoui N, Benhamou D, Vicaut E, Azoulay E, Duranteau J (2012) Renal resistive index better predicts the occurrence of acute kidney injury than cystatin C. Shock Augusta Ga 38:592-597, doi:10.1097/SHK.0b013e318271a39c

27. Dewitte $A$, Coquin J, Meyssignac B, Joannès-Boyau O, Fleureau C, Roze H, Ripoche J, Janvier G, Combe C, Ouattara A (2012) Doppler resistive index to reflect regulation of renal vascular tone during sepsis and acute kidney injury. Crit Care Lond Engl 16:R165, doi:10.1186/cc11517

28. Schneider AG, Hofmann L, Wuerzner G, Glatz N, Maillard M, Meuwly JY, Eggimann P, Burnier M, Vogt B (2012) Renal perfusion evaluation with contrast-enhanced ultrasonography. Nephrol Dial Transplant Off Publ Eu Dial Transpl Assoc - Eur Ren Assoc 27:674-681, doi:10.1093/ndt/gfr345

29. Schneider AG, Schelleman A, Goodwin MD, Bailey M, Johnson L, Bellomo R (2015) Contrast-enhanced ultrasound evaluation of the renal microcirculation response to terlipressin in hepato-renal syndrome: a preliminary report. Ren Fail 37:175-179, doi:10.3109/0886022X.2014.977140

30. Schneider AG, Goodwin MD, Schelleman A, Bailey M, Johnson L, Bellomo R (2014) Contrast-enhanced ultrasonography to evaluate changes in renal cortical microcirculation induced by noradrenaline: a pilot study. Crit Care Lond Engl 18:653, doi:10.1186/s13054-014-0653-3 